\title{
Design of Equipment Teaching and Training Platform Based on SCORM
}

\author{
YU Hui ${ }^{1,2, a}$, SUN Wenzhu ${ }^{2, b}$ \\ ${ }^{1}$ Naval Aviation University, YanTai, China \\ 2 Naval Aviation University Qingdao Branch, QingDao, China \\ athinkfun@126.com, bsunwenzhulm@163.com
}

\begin{abstract}
Keywords: SCORM, SCORM expansion, Learning management system, training system, equipment teaching

Abstract. The thesis analyses the problems in current equipment training system and build up an integrated training management platform of resource, organization, teaching, training, learning and performance measurement. The platform deals with courseware, e-textbook, teaching plan, question bank, virtual simulation training system and semi-physical simulation training system as an overall resource to carry out organization, implementation, interaction, tracking, assessment and management under the guidance of teaching program. The efficiency and quality of equipment training are improved in the process of teaching practice, self-learning, examination, evaluation, optimization and reimplementation.
\end{abstract}

\section{Introduction}

As the main teaching practice of post education in military engineering academy, equipment teaching takes skill training and quality improvement by practice as the principle things, in which the cultivation of learners' capability relies on the priority of practice and the combination of theory and practice.

In traditional equipment teaching, the separation of time and space of theory, experiment and practice doesn't comply with the cognitive principle. The development of equipment-utilizing capability would be lagged due to long study duration and low efficiency. And the lack of sharedness and interaction of teaching materials among academies poses a problem[1].

On the contrary, equipment teaching is characterized by post-orientation, diversity of equipments, practical contents, differentiation of students, lifelong learning and so on, that demand teaching content' adaptability to different students and objective, that will bring about the sharing and reuse of teaching content in training of different levels about equipments in different stage of life. In addition, the informatization through the process of teaching organization, planning, implement and assessment will improve teaching quality and efficiency. The properties of equipment training, that are short-cycle, informatization and reusability, provide the impetus for its modernization.

"Virtual simulation training system" and "semi-physical simulation training system" have been widely used in equipment training, whose teaching/training auxiliary functions make it the increasingly important role in teaching resources[2]. This thesis develops the SCORM standard with the reference of advanced distributed learning put forward by ADI organization of DOD of America and advances the idea of teaching/training resource, which includes courseware, virtual simulation training system and semi-physical simulation training system. Trackable smallest sharable objects in simulation software resources are defined with the reference of the SCORM standard. A platform of equipment training system is set up for the management and assignment of teaching resources to achieve the fusion of theoretical teaching and practical teaching in one space-time. And the management of all the activities throughout the training period can help to realize the modernization of teaching and training.

\section{SCORM standard and its expansibility}

Set by ADL Organization of US DOD, SCORM[3] (Sharable Content Object Reference Model) is a general standard of teaching material production and content development. Three standards are defined in Version III of SCORM 2004: CAM (Content Aggregation Model), RTE (Run-time 
environment) and SN (Sequencing and Navigation), in an attempt to achieve reusability, accessibility, interoperability, durability of learning content to improve education modernization and the following objectives:

(1) To provide the learner anytime and anywhere with high-quality education, training and assistance, that are appropriate for different student's demands, knowledge background, interests and cognitive system.

(2) To shorten the time and low the cost of developing teaching materials, and to further the accessibility of teaching materials among platforms via reuse and sharing.

CAM organizes teaching materials for identification, classification, search and access to reach the goal of sharing and reuse, and explicit the method of transform material into course; RTE supports the interaction of LMS (Learning Management System) and courseware; SN provides the individualized sequencing model.

Content model consists of asset, SCO, Content Organization. Asset refers to the data to present the learner, such as words, pictures, animation, and sound. SCO is the assemblage of one or more assets that are transmittable between SCORM running environment and LMS. Content Organization shows the organization of learning activity.

SCO is the smallest traceable shared object and the base of courseware's reusability and interactivity. Reusability and sharedness is achieved via the binding of SCO and meta-data that makes it traceable and accessible in knowledge base. The interactivity of SCO with LMS by API enables Learning Management System to track it.

Content package is comprised of manifest and physical resource files as shown in figure 1.

Content Package

\begin{tabular}{|c|}
\hline Manifest \\
\hline Meta-data \\
\hline Organizations \\
\hline Resources \\
\hline (sub) Manifest (s) \\
\hline Physical Files \\
(The actual Content, \\
Media Assessment, and \\
other file)
\end{tabular}

figure 1 Conceptual Content Package

In figure 1, meta-data is the data describing content package to satisfy data's query and access, resulting in indexing and reusing data[4].

API is a communication mechanism to carry out message transmission between SCO and LMS, through which the activity of start, end, access, store, etc, can be implemented. Data model describes the message transmission model between SCO and LMS, such as tracking information of SCO, complement state of SCO and result of test. LMS must maintain the status information from SCO data model in learner conversation.

Extended meta-data[2] can be used to describe element when Core meta-data defined by LOM sometimes are not suitable to Organization. Two kinds of extension mechanism are acceptable by LOM: XML element extension allowing adding new element into meta-data case and word extension. SCORM can create and use words and marks of Organization beside the recommended IEEE-defined words.

\section{Training System Platform}

Equipment teaching and training system platform makes content extension based on LMS for purposes of tracking and interaction between teaching and self-learning/training, planning and utilizing resources comprehensively, tracking and evaluating teaching activities, whole-process 
informatization management of training, to make best use of resource and maintain optimum training effect in dynamic process.

The objectives of Equipment Teaching and Training System Platform are the realization of informatization, convenience, interoperability, and optimization in the process of teaching planning, implement and assessment and improvement. In addition, the platform is designed to share and reuse training resource and to integrate production and application.

Informatization refers to whole-process track, implement and management in teaching practice. Convenience means quick response in meeting the demand of new equipment in service in the aspects of teaching preparation, course preparation and textbook compilation, or even establishing training program and organizing teaching materials ahead. Interaction means the information interaction and tracking between shared objects and platform in the process of planning and practice. Optimization is the ability to carry out real-time tracking as well as evaluation and optimization so as to achieve the best efficiency and quality in practice.

When it comes to sharing, all the training resources, such as plan, programme, textbook, courseware, simulated training system and semi-physical simulated training system, are made into content mode according to SCORM standard. In addition, equipment supporting resources in system can be shared among research institutes, academies and army in different phases of whole-progress equipment training. Reusability involves 3 aspects: resources with copyright data and updating data that are up to the standard in edition, revision and correction can be further optimized and reused; the unified standard during resources' release and application makes shared content objects usable in other training systems; shared content objects can be used in sub-systems of management platform. The integration of resources management, organization, teaching, training, learning and assessment is the unified management on supporting materials and the adoption of single platform to track, assess and manage teaching activities and performance in whole process.

The users of equipment teaching/training system platform involved in all the teaching activities includes teaching administrator, teacher, learner, resource developing personnel and system maintenance personnel, who make use of the platform to take up their duty-bound works, as detailed in the following.

a) Teaching administrators are the manager and the initiator of teaching activities, who are responsible to work out training programme and plan, track teaching schedule and effect, collect teaching results, regulate learners and teachers, and optimize training procedure and plan. They play the main role in management, tracking, inquiring, collecting and analyzing statistics, feedback and scheme revision.

(1) management: management on training scheme, teaching programme, textbook, teaching plan involves importing, revising, deleting, optimizing and maintaining scheme and plan; regulating and browsing teaching materials and teaching plan; checking information about copyright, amendment and approval; supervising teacher and learner.

(2) Tracking: real-time check and track schedule effect and results in training and studying.

(3) Inquiry: check information on personnel, teaching and studying state, teaching progress, results and so on.

(4) Statistic analysis: collect and analyze scores, teaching task load and effect contrast.

(5) Optimization: revise and optimize training scheme and teaching plan according to statistics and follow-up information to raise training efficiency and quality.

b) Teachers are the organizers and implement object of teaching activities to compile textbook and teaching plan, implement teaching practices in proper teaching methods according to teaching schedule, set exam and assessment, and provide results and evaluation.

(1) Preparation: compile, manage and make public e-textbook and e-lesson plan by Asset, SCO and simulated resources.

(2) Implement: run courseware, visual simulated training system, semi-physical simulated training system via platform to carry out classroom teaching and field training.

(3) Assignment: release e-textbook, homework, practical content or self-learning courseware on the platform. 
(4) Exam and assessment: online exam about theoretical content and online assessment about practical content. Setting questions, making and keeping test paper, examination and assessment regulation, automatic or manual marking, evaluation and so on.

(5) Assessment: collect and report test scores, assess and analyze course teaching, proposals of improving teaching/training

c) Learners are the object and main body in teaching/training, whose activities include in-class study, after-class study, on-site operational training, assignment, exam and assessment, learning feedback, inquiry on rate of progress and results[5].

d) Resource developers are in charge of the development, management and service of teaching materials and database. Teaching/training materials include courseware and SCO package, shared virtual simulated object package, image virtual simulated SCO package of semi-physical simulated training system (each corresponding virtual simulated training system to semi-physical simulated training system can synchronize totally training records.) databases includes teaching resources database, teaching management database, tracking and analysis database, user management database, exam database, score records database for the management of teaching materials, teaching practice and personnel.

e) Routine maintenance manager is in charge of the normal and safe running of system, involving the functions such as user login, authority setting and altering, log supervision and analysis, use record and analysis, BUG record, back-up, recovery.

f) User and resource management: all users should have an ID and get access to usage tracking and learning tracking after login. The function of user management refers to the management of user in platform.

\section{Platform function module design}

\section{Architecture of platform}

Equipment teaching/training system platform is designed on the basis of full-process teaching management, which includes educational administration, teaching plan, textbook compilation, in-class teaching, after-class self-study, after-class self- training, centralized test, teaching assessment, optimization of training system. The platform can exert management on educational administration, resource development, teaching practice, self-study/training, assessment, evaluation, optimization as an integrated system.

The platform adapts the architecture of 3 layers based on B/S: supporting layer, middleware layer and application layer, as shown in figure 2. User's application layer is comprised of 7 sub-systems and various resources (courseware, question bank and simulated software).

\section{Platform-based course system}

There are two kinds of objects under the management of equipment teaching/training system platform: teaching resources and training objects. Regulators include teacher and teaching administrator. The core content of teaching is teaching materials. In the perspective of platform system, teaching materials expand from traditional textbook and multimedia into e-teaching material, which support pictures, audio, video as well as simulated training software. The organization of teaching materials is shown in figure 3.

Elements such as multimedia and simulated software are called the resources, which can be organized into content webpage with topic as the core. Content web pages are formed into lesson according to chapters and sections; lessons into courses according to course organization; course into curriculum system. The organization flow of chapters and sections in course is shown in figure 4. 

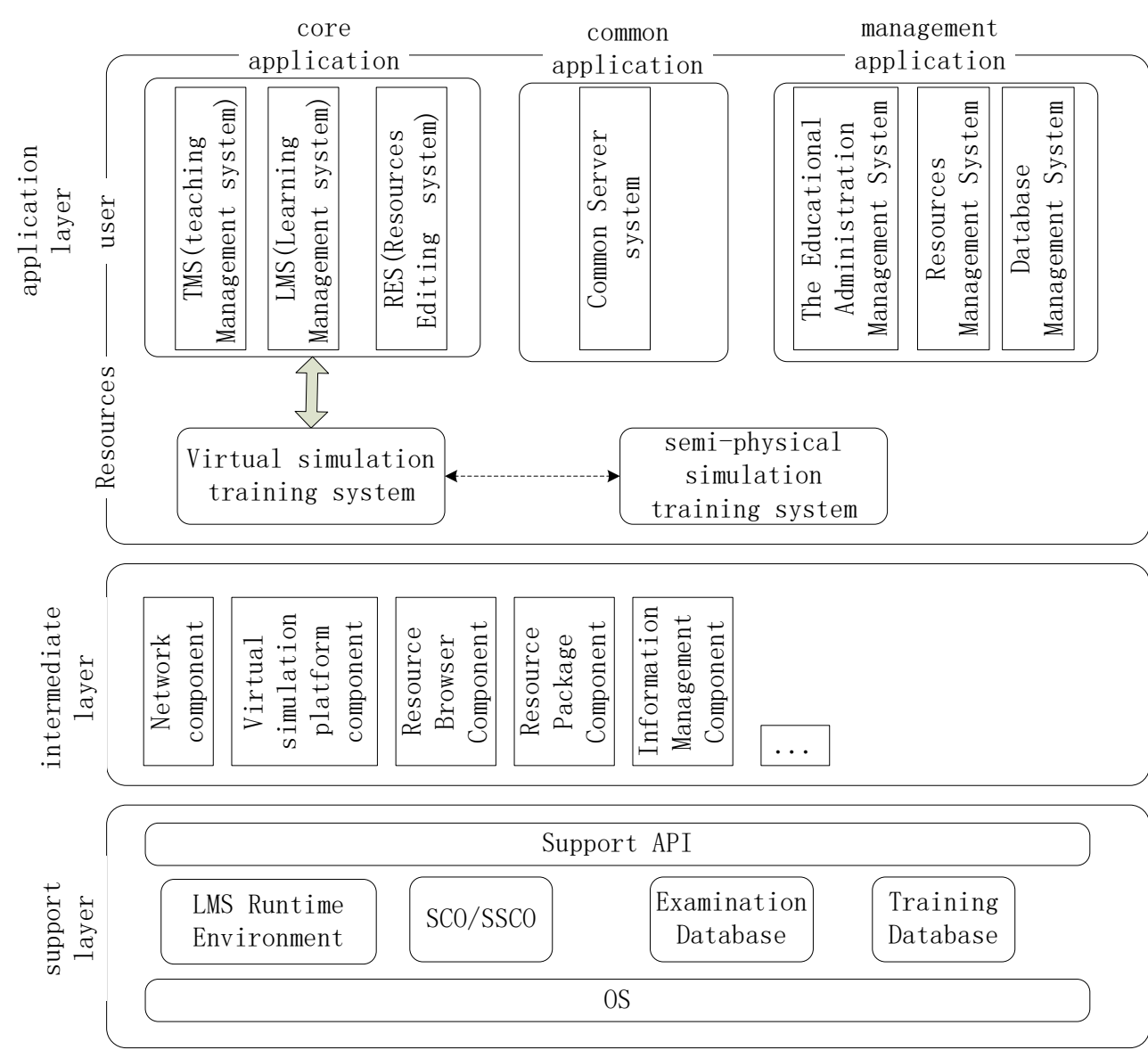

figure 2 the Three Layer Architecture of the Platform

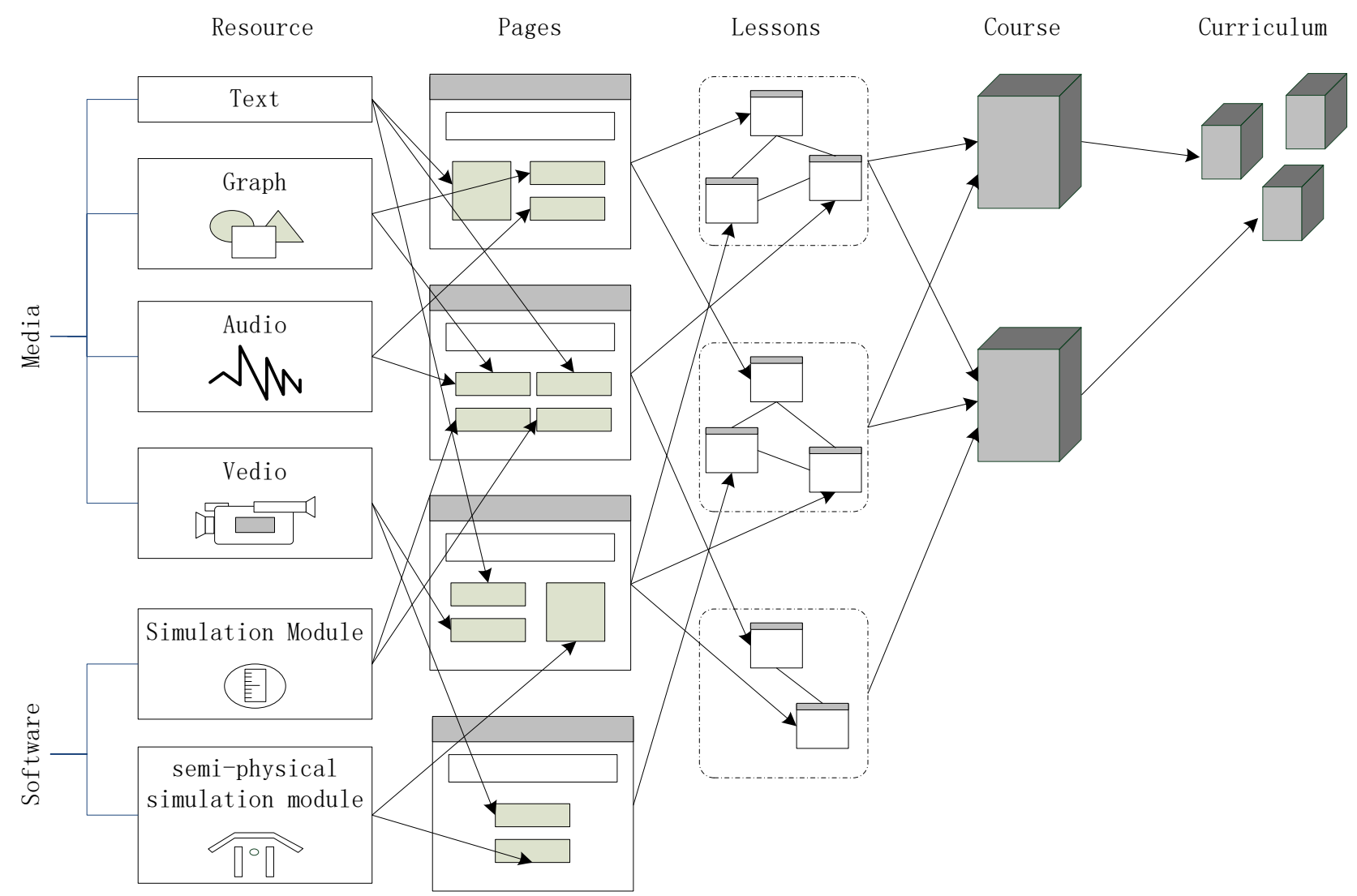

figure 3 Curriculum Organization Hierarchical Structure 


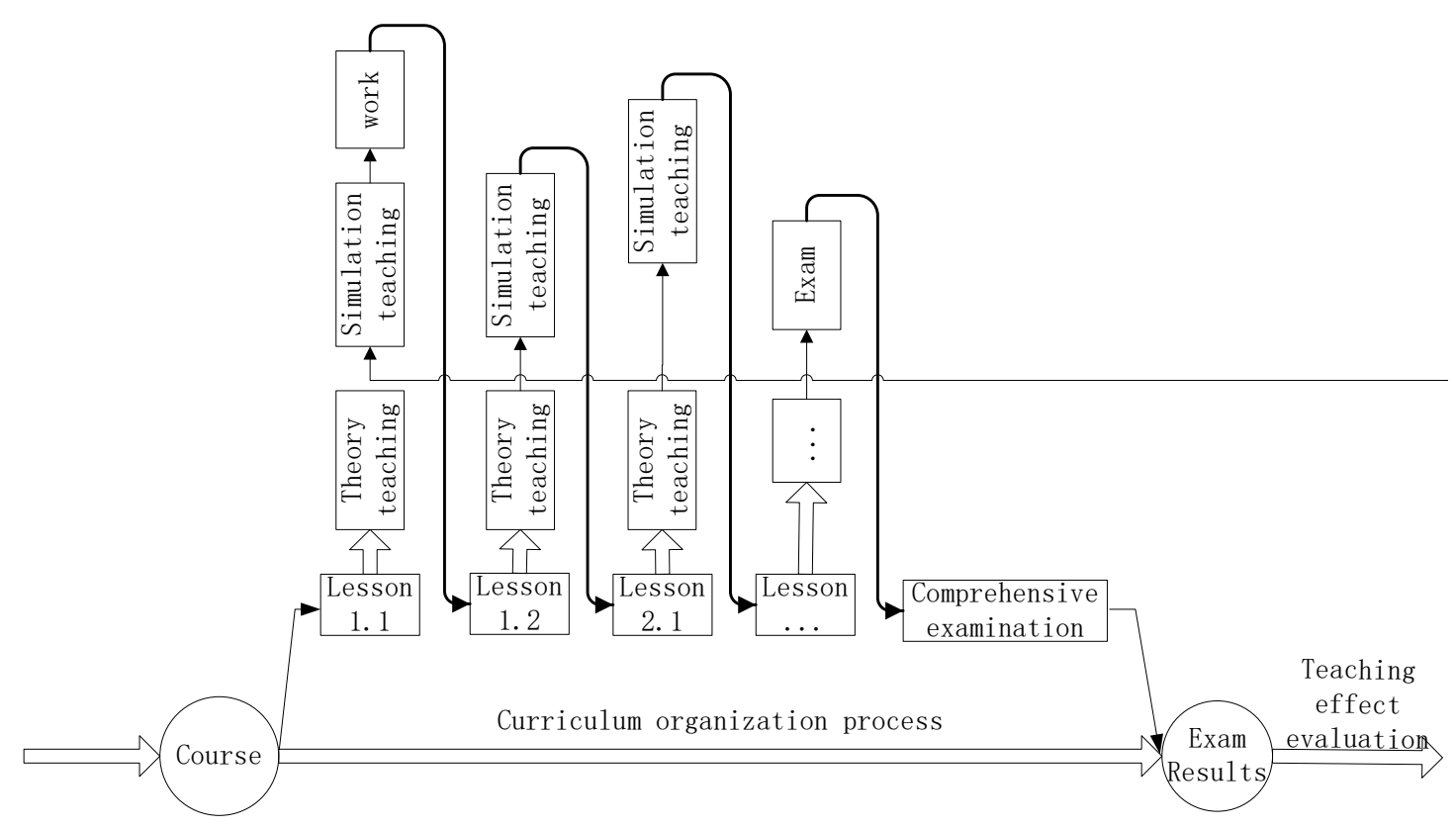

figure 4 Curriculum Organization Process

One chapter of the e-textbook is the integration of multimedia such as text, image, audio and video, and software such as virtual training and simulated training. User can utilize them in organization sequence of content webpage to learn and train, when simulated software can be demonstrated and explained simultaneously with multimedia.

\section{Conclusions}

Giving priority to interaction, reuse, tracking and informatization, equipment teaching/training system platform treats courseware, question bank, virtual simulation training system and semi-physical simulation training system as an integrated teaching resource. The merging of courseware, virtual simulation training, semi-physical simulation training and testing, in addition to progress tracking and interaction, is achieved in both class teaching and self-learning.

The platform expands SCO objects as well as LMS functions and integrate management, implement, tracking as a whole in full period of teaching/training, which widens the application range of SCORM; Moreover, it improves the efficiency and quality of equipment-oriented information teaching due to its adaption to practical teaching' s features and demands, which make full-progress informatization and optimization possible.

\section{References}

[1] Gong Housan, Research on International Standardized Profile for E-Learning Technology Standard Architecture[D]. Wuhan:Huazhong University of Science and Technology, Hubei 430074, P.R.China February, 2007.

[2] LIN Tao, Design and Study on Virtual Simulation System about Warship Training[J]. Computer Simulation, 2012, 29(1): p. 277-280.

[3] The Sharable Content Object Reference Model (SCORM) Advanced Distribute Learning(ADL)[OL]. <http://www.adlnet.org/index.cfm?fuseaction=SCORDown.>

[4] Advanced Distributed Learning Initiative. SCORM 2004 4th Edition Content Aggregation Model(CAM)Version 1.1[EB/OL].:http://www.adlnet.org/,2009.

[5] LI Jian-wei, Learning Management System Design Based on SCORM Standards[J]. Modern Educational Technology, 2013, 23(5): p. 98-102. 